\title{
Correction to: Phases and Mechanisms of Embryonic CardiomyocyteProliferation and Ventricular Wall Morphogenesis
}

\author{
Yaacov Barak ${ }^{1} \cdot$ Myriam Hemberger $^{2} \cdot$ Henry M. Sucov ${ }^{3}$ (I)
}

Published online: 4 November 2019

(c) Springer Science+Business Media, LLC, part of Springer Nature 2019

\section{Correction to: Pediatric Cardiology (2019) 40:1359-1366 https://doi.org/10.1007/s00246-019-02164-6}

The original version of this article unfortunately contained a mistake. In reviewing the phenotype associated with Mapk14 (p38alpha MAPK) mutation as evaluated by Adams et al. (2000) using tetraploid aggregation chimeric embryos, the authors mistakenly stated that rescue of embryo lethality was short-lived and that embryos died two days later of nonplacenta-related causes. In fact, as reported by Adams et al. (2000), when the placental defect of global null embryos was rescued, p38alpha(-/-) embryos developed to term and were normal in appearance. The authors apologize for the error.

Publisher's Note Springer Nature remains neutral with regard to jurisdictional claims in published maps and institutional affiliations.

The original article can be found online at https://doi.org/10.1007/ s00246-019-02164-6.

Henry M. Sucov

sucov@musc.edu

1 Department of Obstetrics, Gynecology and Reproductive Sciences, Magee-Womens Research Institute, University of Pittsburgh, Pittsburgh, PA, USA

2 Departments of Biochemistry \& Molecular Biology and Medical Genetics, Cumming School of Medicine, University of Calgary, Calgary, AB, Canada

3 Department of Regenerative Medicine and Cell Biology, and Division of Cardiology, Department of Medicine, Medical University of South Carolina, Charleston, SC, USA 